\title{
GILBERTO FREYRE: A CIDADE COMO PERSONAGEM¹
}

... a identidade do lugar resiste ao fluxo do tempo.

Thomas Mann

É inegável o apego de Gilberto Freyre ao Recife, de modo a dedicar-se, logo após a publicação de Casa-grande \& senzala a escrever um guia sobre a cidade. Outros trabalhos sobre Recife-Olinda, cidades gêmeas, aparecerão ao longo dos anos: Sobrados e mucambos, Olinda: $2^{\circ}$ guia prático, histórico e sentimental de cidade brasileira, Assombrações do Recife velho, O Recife, sim! Recife, não! O romance Dona Sinhá e o filho padre é um desses exemplos. Através das reflexões que faz sobre a cidade nas várias fases de sua produção é possível captar o desenrolar do desenho dos conceitos e a consolidação de seu método aplicados no conjunto de sua obra.

Nos livros escritos nos diferentes momentos, a cidade ganha significações diferentes. Mas, desde sempre, as cidades o atraíram, talvez não, como dizia Marco Polo, pelas suas sete ou setenta e sete maravilhas, mas pelas respostas que davam a suas perguntas (Calvino, 1990: 44). Por exemplo, quando estudante nos Estados Unidos chega pela primeira vez a Nova York, em carta de 17 de janeiro de 1921 a Oliveira Lima, fala de seu entusiasmo pela cidade:

Nova York está cheia de museus, bibliotecas, jardins, monumentos, casas velhas de eras desfeitas, cantos cheios de cor e interesse, onde a gente imagina estar em terras distantes - como o bairro árabe, com seus bazares e suas cores estridentes, o chinês, com suas lanternas e seus amarelos, de olhos oblíquos e passinhos miúdos, o judaico e outros. Sempre há novas peças nos teatros aos quais a afluência é enorme. Há lugares onde ouvir boa música (Gomes, 2005: 63).

Essas palavras são significativas do interesse amplo de Gilberto Freyre pelas coisas, pessoas, lugares, artes, ideias, traço que marcará fortemente suas pesquisas e escritos e o destacará como estudioso da terra, do povo e da história brasileiros.

Quando viaja à Europa, chegando a Paris, o espírito curioso e inquieto, já patente quando se refere a Nova York, o leva a escrever ao mesmo amigo:

21 dias já em Paris! Não parece. O tempo voa. [...] Cada dia descubro aqui encanto novo ou novo interesse. Mas isso entre as velhas coisas, cá nesta rive gauche que meu querido Huysmans tanto amava. Saint-Chapelle, Notre Dame, Saint Severin, 
Saint Suplice, as velhas ruas, o bom Paris medieval da Ile de La Cité - que encanto, que encanto! (Gomes, 2005: 144-145).

Dedica-se a frequentar teatros, ouvir música, visitar museus, igrejas, a apreciar ruas e bairros da cidade, a ler jornais e revistas, conforme narra em cartas a Oliveira Lima. Relata, em 30 de agosto de 1922, os diferentes contatos estabelecidos, concluindo: " $E$ vou compreendendo, ou antes, procurando compreender os pontos de vista. Compreender - não é este o grande Sport intelectual, o jogo de xadrez que nos diverte e move as idéias durante esta noite de inverno que é a vida?" (Gomes, 2005: 147). Na Alemanha, em 24 de outubro de 1922, registra: "Encantou-me logo Nuremberg com seu ar medieval e suas gordas torres. [...] À beira de águas quase paradas, casas pensativas, um arvoredo também pensativo" (Gomes, 2005: 153).

O que prende a atenção nessas notas é um elemento que estará presente constantemente na obra de Gilberto Freyre: a busca do passado das cidades, expressos na arquitetura, no traçado, na concepção. Ou ainda, um ponto que será constante em suas análises futuras: o lugar da tradição, que será central na edificação de sua obra. O interesse presente no jovem se alonga no escritor maduro, interesse ressignificado pelo tempo e lugar.

A questão que dirige minha reflexão neste artigo é a seguinte: será que se pode inferir o trajeto conceitual e a metodologia do autor a partir desse "começo"? O início poderia ser considerado como um momento de tomada de consciência daquilo que vai orientar a reflexão de um escritor ou sua interpretação? Seu método decorreria, desenvolvendo-se posteriormente, desse ponto de partida? Seria a metodologia empregada resultado de um avanço crítico e aperfeiçoamento instrumental desse "começo"? Edward Said, em Beginnings: intention and method (1975), sugere três pontos básicos para orientar a leitura da obra de um autor: inícios ou origens, intenção e método. Sigo sua sugestão, mesmo considerando difícil definir objetivamente a intenção como condutora da escritura. Prefiro substituir o termo por preocupação e/ou empenho. Tomo, nessa direção, a proposta de Arcadio Diaz Quiñones em sua análise sobre os "princípios" (Diaz Quiñones, 2006). Ao estudar Fernando Ortiz afirma: "Nos beginnings de Ortiz há uma preocupação com a viabilidade do projeto republicano e a 'regeneração' depois da Guerra da Independência. Um dos principais empenhos de Ortiz é definir o lugar e as qualidades da elite" (Diaz Quiñones, 2011: 112, grifos meus).

Tendo utilizado conversa com amigos por meio de correspondência para ilustrar o interesse de Gilberto Freyre com a temática da cidade, volto agora para alguns de seus primeiros artigos de jornal, nos quais a argumentação aparece de forma mais clara. Em escritos do Diário de Pernambuco para o qual colaborou desde 1918, portanto antes das citadas cartas sobre Paris e Nuremberg, na série intitulada $\mathrm{Da}$ Outra América, encontramos alguns exemplos importantes da origem temática e da preocupação interpretativa. Em 18 de setembro de1921: 
"Curiosa cidade. Montreal. Francesa, inglesa, americana. Raramente ela mesma. [...] sente-se a falta de algo definitivo. É caráter. Ou melhor, o que os ingleses chamam 'cor local'" (Freyre, 1964: 72). Ou ainda, em 14 de março de1920: "Des Moines afasta-se pouco da fisionomia comum das cidades americanas. Meio industrial, a fuligem de suas chaminés [...] negreja-lhe os edifícios. [...] não faltam igrejas francamente belas. Que seria das cidades americanas se lhes arrancassem as igrejas?" (Freyre, 1979a: 71). Antes, em seu primeiro artigo como correspondente do jornal, em 3 de novembro de 1918: "Escrevo de Louisville. É uma cidade antiga. Os kentuckianos gostam de chamá-la 'our good old city'. Ao mesmo tempo é um empório industrial onde fumegam os bueiros de não sei quantas fábricas" (Freyre, 1979a: 39). Ou quando conta, em 20 de agosto de1922, sobre sua visita a Amy Lowell, em que compara "as ruas tortas, coloniais de Boston" ao bairro de ricaços aristocráticos no qual vive a escritora, cheio de "palácios que imitam os estilos todos". Longe de criticar a mistura estilística, Gilberto elogia o local por seu arvoredo, olmos na maioria, que confere ao conjunto uma unidade que dá "à paisagem a significação a que os demais elementos parecem subordinados. De fato, a emoção que se apossa de nós, a percorrer Brooklin, é de repousada beleza" (Freyre, 1979a: 232-233).

Nota-se nesses escritos o apreço de Gilberto Freyre pelo passado, pelos elementos antigos que compõem a(s) cidade(s). Talvez um leve traço de objeção ao moderno. Porém, nesses textos não aparece de modo explícito o empenho na defesa das tradições como um dos marcos que configuram a identidade da cidade e que virá a ser um dos elementos fundamentais de sua interpretação sobre a sociedade brasileira.

É importante assinalar que a questão - a que tipo de tradição recorrer? -, embora não apareça ainda nos escritos de Freyre, está presente em suas preocupações. Estando em Columbia, anota em seu diário:

Converso com o Professor De Onis sobre assuntos hispânicos. Ele se espanta do fato de eu não só aceitar como desenvolver uma concepção de civilização que põe o Brasil do mesmo modo que Portugal no conjunto hispânico de nações. De ordinário, ele me explica, os portugueses reagem com excessivo furor emocional contra a concepção hispânica de civilização, julgando-se vítima de um imperialismo espanhol, perigoso e absorvente (Freyre, 1975: 54-55). ${ }^{2}$

Ainda, segundo o diário, nesse momento lê vários autores espanhóis: Lulio, Vives, Pio Baroja, Ganivet, Unamuno, Ortega y Gasset, para citar alguns. Diaz Quiñones, ao analisar a obra do portorriquenho Antonio S. Pedreira, mostra que o pano de fundo de seu livro Insularismo, de 1934, é o hispanismo acadêmico nos Estados Unidos, tendo esse autor estudado com Federico De Onis, em Columbia, nos anos 1920 (Diaz Quiñones, 2006: 135-136). É certo que a busca das raízes dos diferentes países, voltada à construção da tradição que remonta ao período colonial, comporta "a invenção de novas - e problemáticas - possibilidades de existência" (Diaz Quiñones, 2006: 133). Se aproximarmos a visão de Pedreira 
e de Freyre, embora ambos estivessem sob a influência do mesmo professor, percebemos que enquanto o primeiro prestava pouca atenção ao mundo afrocaribenho, conforme assinala Diaz Quiñones, o segundo operará, mais tarde, um salto em relação às anteriores interpretações do Brasil, marcando a forte influência racial e cultural dos escravos africanos.

A reflexão sobre o hispanismo institucionalizado na Universidade de Columbia dos anos 1920 resulta em um ponto comum ao qual os alunos, futuros autores, estarão referidos: a discussão sobre o papel do colonialismo na(s) formação(ões) nacional(ais). Said, em Cultura e imperialismo (1995) lembra a diferença entre as diversas formas de colonização, pois em cada local a organização, as associações, o relacionamento, as instituições e as obras dos autores ganham desenhos diferenciados conforme a situação. Essa diversidade de combinações em relação ao papel da tradição ibérica transformar-se-á no eixo da obra de Gilberto Freyre. Embora a preocupação possa ter lançado uma inquietação em seu espírito, não será nesse momento que tomará sua forma definitiva.

Assinalei anteriormente que a preocupação com a manutenção das tradições ainda não aparece de modo explícito nos artigos citados. Somente naqueles escritos a partir de 1923 a questão se apresentará de modo claro. Assinale-se que nesse momento o autor se encontra de volta ao Recife, depois de cinco anos de ausência. Diaz Quiñones, remetendo a Homi Bhabha, lembra que "os modos de ler e de interpretar têm sua própria história. Na diferença cultural 'muda a posição de enunciação e as relações de interpelação internas; não só o que é dito, mas de onde se diz'” (Diaz Quiñones, 2006: 135).

Como ilustração, aproximo artigo de Freyre publicado em 30 de setembro de 1923 àquele de agosto de 1922, referente à visita a Amy Lovell. "Chesterton disse uma vez que as cidades falam por sinais", isto é, por seus palácios, catedrais, igreja, estátuas, colunas. "Num lugar novo, o principal é compreender seus edifícios e suas estátuas. É o que procura fazer o viajante inteligente". Referindo-se à casa colonial de um amigo no Recife, afirma que ela "tem caráter", pois recorda as casas de engenho. "Faz sentir quatrocentos anos de vida pernambucana - social e econômica". E continua: "num Recife que vai todo virando confeitaria, a arquitetura sóbria de nossos avós se torna estapafúrdia" (Freyre, 1979a: 315-316). Note-se que já não aceita mais a "mistura de estilos" presente no bairro norte-americano em que vivia a escritora, que lhe parecera ganhar unidade pela beleza do arvoredo. Duas semanas depois, em artigo de 14 de outubro de 1923, retoma o tema, com mais ênfase. "Há um prêmio a que o Brasil deve concorrer na próxima exposição internacional. É o de devastador do passado. Devastador das próprias tradições" (Freyre, 1979a: 320). Ou ainda, falando da substituição de antigos edifícios por novas construções, ou pelo descaso da Inspetoria de Monumentos Históricos em dedicar-se à restauração, diz em artigo de 9 de dezembro de 1923: "O que principalmente se impõe no Brasil é uma campanha que nos eduque no gosto da antiguidade” (Freyre, 1979a: 342). 
Numa visita à Paraíba (atual João Pessoa) reclama da arquitetura nova "que se vai deixando toda salpicar de alfenins. [...] É alguma coisa de corrosivo. Alguma coisa a cujo contágio os edifícios à moda antiga parecem incapazes de resistir" (Freyre, 1979a: 347, artigo de 23 de dezembro de 1923).

Os exemplos são inúmeros, indicando defesa das tradições, não apenas direcionada à arquitetura urbana, mas aos elementos locais, dos quais a cidade é símbolo. Ou seja, a "arquitetura de confeitaria" revela os homens - sua vida sua moral, seu gosto. Reclama da mudança dos nomes de ruas do Recife que, antigos e pitorescos, estavam referidos a seus habitantes originários (Rua das Crioulas), a acontecimentos passados (Beco da Facada) ou a mitos e fantasmas (Rua Cruz das Almas). Propõe a instituição do Dia do Passado ou Dia das Coisas Antigas. Lembra, ao comentar o livro de Oliveira Lima, Aspectos da história e da cultura do Brasil, que um dos fatores que levaram o Império à crise foi a falta de respeito às tradições que marcou a corte de D. Pedro II. Reclama da desnacionalização do paladar pernambucano que perde suas referências próprias; dos transportes modernos que acabam com os vagares da delicadeza; do abuso do verbo mudar, que atinge os costumes e aconselha a volta ao hábito de conservar. Em outros termos, aponta tema comum aos escritores brasileiros do decênio de 1920; o mal do transplante de ideias, costumes, legislação etc. Porém, diferentemente daqueles, que denunciam o transplante das instituições como o mal maior presente na formação brasileira, lembra que o lugar diz muito mais sobre a sociedade e os costumes tradicionais expressam a coesão da mesma. $\mathrm{Na}$ cidade esses traços são claros, por este motivo ganha importância em sua reflexão. Um passo maior, nesse sentido, será dado nos livros escritos pelo autor nos anos 1930.

\section{UMA NOVA ETAPA}

Quando me refiro à existência de um passo mais largo entre os escritos de Gilberto Freyre entre 1920 e 1930 refiro-me à adequação de forma e conteúdo presente em seus livros clássicos. Estilo, argumentação, contexto, narrativa, teses ganham outro arranjo em Casa-grande \& senzala e Sobrados e mucambos, para citar apenas dois textos. Parece-me que os exemplos alinhados anteriormente são suficientes para ilustrar a mudança de narrativa, mas não se trata de algo tão simples. Aqueles apresentados nos anos 1920 - cartas e artigos - podem ser considerados "formas menores" se comparados a um livro. Não assumo o risco de enfrentar essa polêmica, mas arrisco-me a sugerir o lugar que alcançam no itinerário do autor.

Limito-me a refletir brevemente sobre os artigos. Embora Gilberto Freyre sempre os tenha chamado "artigos de jornal", creio que em grande parte poderse-ia denominá-los crônicas, pois assumem a função de captar elementos coti- 
dianos da vida, em geral da vida das cidades. Referindo-se a escritos de José Marti, Julio Ramos mostra como a crônica constitui-se, para esse autor, em meio adequado para a reflexão sobre a mudança da sociedade. Mais do que isso, como essa forma literária operou, no século XIX, na consolidação da literatura latino-americana (Ramos, 1989: 113). Penso que, do mesmo modo, podemos atribuir essas características aos primeiros escritos de Gilberto Freyre. Cito alguns pontos em que essas crônicas exerceram papel importante na continuidade de sua trajetória e na inovação de sua análise posterior. Primeiramente, o autor aponta a importância desses artigos para o aprimoramento de sua escritura. Na introdução ao volume em que aparecem reunidos, relembra seu empenho, quando jovem, em encontrar novas formas de expressão literária em português, aproveitando-se do recente conhecimento de autores e influências vindas das "línguas inglesa, francesa e espanhola" (Freyre, 1979a: 27). Afirma que é então que se constitui o estilo gilbertiano, pois buscou adaptar essas influências a seu "próprio respirar, ora inquieto, ora tranquilo". Procurou "Desenvolvê-las, individualizando-as, modernizando-as, diferenciando-as das convencionais. Gilbertinizando-as nos seus ritmos e na sua possível musicalidade" (Freyre, 1979a: 28).

É certo que se trata de avaliação feita mais de 50 anos depois da escritura daqueles trabalhos, o que poderia significar atribuição posterior de sentido. Porém, essa posição assumida pode ser também captada nos textos do período. Ilustrando: numa crônica de 17 de maio de 1925, com o título "Viver às claras", mostra como tema e ritmo já refletem a influência de um dos escritores citados naquela introdução. Diz Gilberto:

[...] uma casa iluminada por igual não predispõe a família para aqueles serões e aquele aconchego de outrora, com a leitura dum romance de Alencar ou do Almanaque de Lembranças Luso-Brasileiro, depois do jantar, junto ao candeeiro grande e gregário. [...] a luz de azeite ou petróleo atraía e aconchegava pelo estranho prestígio de sua debilidade, ao contrário da luz elétrica que dispersa e desune (Freyre, 1979b: 162).

São quase as mesmas palavras escritas por Ángel Ganivet no final do século XIX, autor lembrado no artigo, mas não citado em relação à temática que busco apontar.

O braseiro e a lamparina têm sido na Espanha dois firmes sustentáculos da vida familiar, que hoje se vai afrouxando por várias causas, entre as quais não é menor o abuso da luz. O antigo lar não estava constituído somente pela família, mas também pelo braseiro e pelo candeeiro, que com seu calor escasso e sua luz débil obrigavam as pessoas a se aproximarem e a formar um núcleo comum. Ponha-se um foco elétrico e uma estufa que iluminem e aqueçam um aposento por igual e se terá dado um primeiro passo para a dissolução da família (Ganivet, 1996: 38). ${ }^{3}$

A diferença está dada tanto pelo trópico como pelo tempo, mas a defesa das tradições é a mesma, mesmo o lamento pelas perdas trazidas pela modernidade. ${ }^{4}$ 
Outro elemento importante presente em relação a esses primeiros textos é o papel que exerceram no aprimoramento do método a ser desenvolvido por Gilberto em seus livros, que pode ser visto sob dois aspectos. De um lado, a necessidade de observação dirigida, aprofundada e constituída em instrumento metodológico; de outro, a atenção aos elementos que constituem o cotidiano de um povo, de uma cidade, de um grupo. Sobre o primeiro ponto, em artigo de 10 de abril de $1921 \mathrm{diz}$ :

O simples artigo para jornal apresenta dificuldades à pessoa conscienciosa. A tentação de generalizar é forte. Raros, os que dela sabem esquivar-se. [...] Em viagem ou em estudo em terra estrangeira precisa o indivíduo guardar-se da ligeireza de opinião, trocando-a pelo que o americano chama earnestness e que é a vontade de ir ao fundo das coisas (Freyre, 1979a: 103-105).

Sobre o estudo do cotidiano como forma de construção da história social aparece explicitamente no mesmo texto que propõe a necessidade "do ecletismo de opiniões morais, disposição de ler os jornais da terra [...], de misturar-se com o povo, de aprender-lhe o idioma e os hábitos" (Freyre, 1979a: 103-105).

O aprofundamento dessa perspectiva dar-se-á na aplicação do método que ancora a pesquisa realizada para a obtenção do título Master of Arts, na Universidade de Columbia, em 1922. ${ }^{5}$ Parte do material dessa investigação aparecerá no ensaio "Vida social no Nordeste", publicado em 1925 no Liuro do Nordeste, comemorativo do centenário do Diário de Pernambuco. Vale lembrar que o período estudado é o século XIX e as mudanças ocorridas em seu curso. Por tratar-se dessa época, formas de organização, usos, costumes, comportamento estão referidos simultaneamente à cidade e ao campo. Não só pelo momento estudado, como pela temática, é possível considerar equivocada a afirmação que aparece em várias leituras sobre a obra de Gilberto Freyre apontando a continuidade entre esse texto e suas teses em Casa-grande \& senzala, livro dedicado ao período colonial. ${ }^{6}$ Não só a tese sobre o patriarcado como sobre a mestiçagem, centrais no livro de 1933, aparecem na exposição sobre a vida social do Nordeste em meados do século XIX de modo ambíguo.

O patriarcado é visto principalmente como modo de vida e o patriarca ainda não aparece como ator fundamental na ordenação da sociedade, tese central na série Introdução à história da sociedade patriarcal no Brasil, formada pelos livros Casa-grande \& senzala, Sobrados e mucambos e Ordem e progresso. Algumas passagens do ensaio "Vida social no Nordeste" ilustram esse enfoque; "Nos tempos patriarcais de antes da abolição vivia-se mais do que hoje vida de família" (Motta, 1979: 78). Conta, ainda, sobre a "intimidade" que marcava os costumes, exemplificando com as longas visitas inesperadas feitas por famílias amigas aos engenhos. Ou "À vida dos engenhos faltam [hoje] as condições de permanência e ritmo patriarcal de outrora" (Motta, 1979: 79). Burke \& Pallares-Burke (2009) referem-se ao texto apresentado em Columbia mostrando "a importância dada 
pelo autor à 'história sensual'", evocando os cheiros e rumores da rua e, na casa as vozes espalhafatosas das sinhás gritando com os escravos.

Sobre a questão racial, afirmam os mesmos autores:

[...] quanto à defesa da miscigenação, uma das marcas da futura grande obra de Freyre, ainda não havia sinal de que discordasse das idéias em voga sobre as implicações patológicas da mistura de raças. Nessa época, ele ainda via o sangue africano como uma mancha no Brasil e um obstáculo para seu desenvolvimento (Burke \& Pallares-Burke, 2009: 74).

A respeito da mestiçagem Gilberto assinala no ensaio as diferentes opiniões dos autores sobre ser o Nordeste a zona "mais colorida pela commixtão de sangue; a mais contaminada pelo sangue negro" (Motta, 1979: 90) e, aparentemente, não assume posição diante delas. No entanto, algumas linhas depois, ao citar um viajante inglês que relata ter encontrado, no Rio de Janeiro, mulatos refinados, assegura serem esses casos excepcionais e pouco representativos de mulatos que "apresentem a sobriedade e a elegância moral que fixam o homem culto. [...] O mestiço que se eleva ostenta uma 'hyperesthesia de arrivismo' às vezes repugnante. É por isto uma criatura cujo contato dificilmente dá prazer" (Motta, 1979: 90). Posição muito distante daquela que assumirá não só sobre a mestiçagem no livro de 1933, como, principalmente em relação ao mulato em Sobrados e mucambos.

Desde 1927, poucos são os artigos com o mesmo teor daqueles publicados a partir de 1918. Em agosto de 1928, Gilberto Freyre, ao lado de José Maria Bello, assume a direção do periódico pernambucano A Província, encarregando-se da escritura de vários de seus editoriais. Não sendo assinados, fica difícil a atribuição autoral definitiva. No entanto, vários temas e mesmo a forma de abordagem dos mesmos permite que reconheçamos neles os sinais do autor. ${ }^{7}$ Nesse momento Gilberto ocupa cargo de secretário-chefe de gabinete do governador de Pernambuco, Estácio Coimbra, pertencente ao partido político proprietário do jornal diário. Editoriais, artigos e notícias voltam-se ao estudo dos problemas nacionais enfocados do ponto de vista da região. ${ }^{8}$ Diferentemente do conteúdo abordado por A Província nas décadas anteriores - a primeira edição é de 1872 -, a partir da nova direção os temas não estão circunscritos apenas "à vida institucional e partidária, mas também à dinâmica da vida social" (Chaguri, 2011: 9). A temática "tradições pernambucanas" está no cerne da discussão sobre o sentido do regionalismo, sendo a cidade Recife/Olinda o locus desse processo. Na primeira edição, assinada por Freyre e Bello, lê-se:

As tradições que valem para nós são as que correspondem à realidade de nossos problemas. Mas nenhum povo se faz e se define num tipo superior de cultura fora do sentido inteligente de suas tradições. Assim as instituições. Elas vivem por uma tradição superior aos excessos do momento, retificando exageros e desmandos, conserva-se o espírito, o caráter, a essência daquela tradição (apud Chaguri, 2011: 10). 
Assumindo a tarefa de defesa da vida local, os editoriais do jornal defendem as ações modernizadoras do governador e qualificam as mudanças urbanas "que, sendo necessárias, devem comportar as particularidades da cidade, preservando sua história e dando relevo a suas tradições" (apud Chaguri, 2011: 11). A conciliação entre tradição e modernização é ponto central nesses editoriais, a articulação entre o antigo e o moderno deveria ser o objetivo das intervenções do "urbanismo verdadeiro, o que se preza em conciliar interesses [...]. A fisionomia tradicional da cidade merece o respeito do urbanista ao mesmo tempo que o problema da higiene e o da circulação" (apud Chaguri, 2011: 11).

No quadro dessa combinação tradicional-moderno abordam-se os problemas sociais, como é o caso das moradias populares; os mocambos" "valorizados como habitação da gente pobre do Recife, destacando a sua característica de adaptação ao meio", onde o sol penetra à vontade (apud Chaguri, 2011: 13).

Em 1930 Gilberto Freyre acompanha Estácio Coimbra ao exílio ${ }^{10}$ fixando-se em Lisboa, onde faz pesquisas sobre o material que servirá de fundamento a Casa-grande \& senzala, a ser escrito a partir de seu retorno ao Brasil (1932) e publicado em 1933. O livro é dedicado ao período pré-colonial e colonial e tem como subtítulo formação da família brasileira sob o regime de economia patriarcal. Embora, dado o momento enfocado, o texto tenha poucos elementos sobre a constituição das cidades, as teses que marcarão o restante da obra freyriana encontram aqui sua formulação principal: mestiçagem, trópico e patriarcalismo. Além disto, nesse trabalho o método de estudo do cotidiano ganhará sua forma definitiva.

A miscigenação, vista por Freyre em seu duplo aspecto racial e cultural, "corrigiu a distância social que doutro modo se teria conservado enorme entre a casa-grande e a mata tropical; entre a casa-grande e a senzala" (Freyre, 1933: XV). E agiu "poderosamente no sentido de democratização social" (Freyre, 1933: $\mathrm{XV}$ ). Sobre a formação patriarcal do Brasil, lembra que esta se explica em "termos econômicos, de experiência de cultura e de organização da família, que aqui foi a unidade colonizadora" (Freyre, 1933: XVII). Mais ainda, o sistema patriarcal "foi um sistema de plástica contemporização" em relação à mestiçagem, à adoção de elementos das diferentes culturas e de adaptação ao meio tropical (Freyre, 1933: XVIII). Em Sobrados e mucambos a forma pela qual esses mesmos elementos operaram na cidade, isto é, no século XIX, foi desenvolvida por Gilberto Freyre. A decadência do patriarcado rural vai alterar a função exercida por esses fatores formadores da sociedade brasileira. ${ }^{11}$

Embora a relação crescimento das cidades e decadência do patriarcado estivesse presente desde a primeira edição, só a partir da segunda edição, em 1951, o subtítulo do livro acentua essa articulação. ${ }^{12}$ Mais que isso, o processo não é mais atribuído, pelo menos no título, ao Brasil. Talvez as críticas recebidas aos primeiros livros, que acentuavam o fato de Gilberto ter estendido às várias regiões do país um relato que só se aplicaria ao Nordeste, tenha operado como fundamento da mudança. ${ }^{13}$ 
Nas duas edições, o capítulo denominado "O engenho e a praça; a casa e a rua", é dedicado a mostrar como na cidade a sociabilidade se altera, definem-se algumas fronteiras entre o público e o privado, modifica-se profundamente a solidariedade e, mais ainda, a estratificação social torna-se visível. A rua é interditada às sinhás brancas, mas por ela transitam livremente as escravas negras. $\mathrm{O}$ traçado urbano configura oficialmente o lugar social dos diferentes grupos: Rua dos Tanoeiros, Beco dos Ferreiros, Rua dos Pescadores, Rua dos Judeus, Rua dos Ourives. Se no período colonial a família era a unidade orgânica que permitia que os antagonismos permanecessem em equilíbrio, na cidade do século XIX a diferenciação social e, portanto, os conflitos aparecem de forma mais clara. Porém, entre a primeira e a segunda edição percebe-se uma diferença na qualificação dos conflitos. Ou seja, embora a condição escrava seja um dos elementos da fricção social, somente na segunda edição a questão racial aparece como tema.

Desenvolvo brevemente a argumentação de Gilberto. Falando do quilombo de Palmares, que chama "República de mucambos" diz, na primeira edição: "Foi a primeira Cidade a levantar-se contra o Engenho - essa cidade socialista de negros; do mesmo modo que foi, em sua técnica de exploração da terra, um movimento de policultura em contraste com a monocultura predominante nos latifúndios dos senhores brancos" (Freyre, 1936: 72, grifos meus). Na edição ampliada, em 1951: "Foi a primeira Cidade a levantar-se contra o Engenho - essa cidade parassocialista de negros; do mesmo modo que foi em sua técnica de exploração da terra, um esboço de policultura em contraste com a monocultura predominante nos latifúndios dos senhores brancos" (Freyre, 1951: 42, grifos meus). Ou, ainda: "Tanto que foi no escravo negro que primeiro desabrochou no Brasil o sentido de solidariedade mais largo que o de família, a capacidade de associação sobre base francamente cooperativista" (Freyre, 1936: 72). Já em 1951: "Tanto que, excetuada a confraria Católica, foi no escravo negro que mais ostensivamente desabrochou no Brasil o sentido de solidariedade mais largo que o de família sob a forma de sentimento de raça e, ao mesmo tempo, de classe: a capacidade de associação sobre base francamente cooperativista e com um sentido fraternalmente étnico e militantemente defensivo dos direitos do trabalhador" (Freyre, 1951: 41-42, grifos meus). Retornando à enunciação das ideias, relembro as já citadas palavras de Homi Bhabha sobre a posição e as relações de interpelação. Parece-me, que no caso dessas passagens da segunda edição de Sobrados e mucambos as palavras vão diretamente em direção a Caio Prado Jr., contrapondo-se à sua interpretação sobre o escravismo na sociedade brasileira. ${ }^{14}$

Creio que com esse exemplo posso demonstrar que Gilberto passou, na sua obra dos anos 1930 e nas que decorrem dela, dos beginnings ao momento seguinte, utilizando-os para ancorar um projeto, chegando, segundo palavras de Edward Said, “à maturação reprodutiva e à maturidade" (Said, 2005: 25). Esse projeto ganhou corpo com os diversos livros que compõem a Introdução à história da sociedade patriarcal no Brasil. ${ }^{15}$ 


\section{DONA SINHÁ: A CASA E A CIDADE}

Em vários livros, não necessariamente ligados ao seu projeto principal de interpretação da sociedade brasileira, Gilberto retorna à temática da cidade - nos já citados Guias de Recife e Olinda escritos nos anos 1930, em Assombrações do Recife velho (1955) e em parte importante de Ordem e progresso (1959). O peso do passado na vida de seus habitantes, as tradições indispensáveis à manutenção da coesão social e as transformações que afetam negativamente essas tradições voltam constantemente a esses escritos. Porém, em Dona Sinhá e o filho padre (1964), livro que se diferencia profundamente das narrativas anteriores, pois se trata de um romance, o tema "cidade" ganha lugar especial.

A ficção de Gilberto Freyre, denominada por ele seminovelas, ${ }^{16}$ já foi comentada por vários autores, entre os quais ressalto a excelente análise de Edilberto Coutinho (1983) que aborda inúmeros aspectos desses textos, mostrando os possíveis diálogos com as literaturas clássica e contemporânea. Em geral, nas leituras feitas, pela temática e narração, os dois romances - Dona Sinhá e o filho padre e O outro amor do doutor Paulo - são aproximados aos livros de Freyre considerados mais importantes - Casa-grande \& senzala e Sobrados e mucambos. Coutinho mostra que a técnica de construção "em abismo" que marca a narrativa dessas novelas, em uma forma mais amena já está presente naqueles dois textos, tese com a qual concordo.

Proponho, neste artigo, referindo-me a Dona Sinhá e o filho padre, uma outra aproximação: com os artigos dos anos 1920 e com o livro de 1959, Ordem e progresso. Porém, antes desse procedimento, é importante conhecer quem participa dos acontecimentos do romance. Respondendo à questão, Coutinho indica como personagens Dona Sinhá, José Maria, seu filho, Paulo, amigo de José Maria, Gaspar Wanderley, irmão de Sinhá. Alguns personagens secundários aparecem: Frei Rosário, Inácia, a mucama, Amaro, o muleque, algumas figuras míticas como Iemanjá ou a moura-encantada, personagens históricos como Dom Vital e Joaquim Nabuco. Acontecimentos reais e fictícios relacionam essas figuras. Assim, estória e história se entrelaçam. Para distinguir o histórico Freyre utiliza o itálico. Sugiro, em minha argumentação, que a cidade do Recife compõe-se como personagem ao lado dos outros e é ela que estabelece a relação entre estória e história.

Trata-se de um "livro-dentro-de-um-livro". Há uma duplicação de narrativa: o narrador que imaginara uma história sobre certa Dona Sinhá e seu filho padre é convocado por uma Dona Sinhá realmente existente que o acusa de abusar de seu nome: "eu não sou nenhuma cômica para alguém escrever minha vida para o público" (Freyre, 1967a: 5). Embora assustado, indagando se tratava-se de um caso metapsíquico, o narrador, com a concordância de Dona Sinhá, decide escrever a história a partir do relato feito por ela. Reflete: "[afinal] não nasci para romancista inventor de casos e personagens; e sim para outro 
gênero de bisbilhoteiro das intimidades da natureza humana: a bisbilhotice do real ou do mais que real" (Freyre, 1967a: 6). É uma das primeiras frases do livro em que o narrador, embora sendo personagem, começa a se identificar com o perfil de Gilberto Freyre, embora em Conversa com o leitor, ao final do texto afirme: "ninguém pense que seja, mesmo remotamente, autobiografia disfarçada; ou biografia romanceada" (Freyre, 1967a: 144). Mas a identificação aparece em várias passagens, quando lembra seu provável parentesco com Dona Sinhá, tanto no papel de narrador quanto como Gilberto Freyre, descendente dos Wanderley. Por exemplo, quando cita no livro o "velho Freyre" (Freyre, 1967a: 42) - forma pela qual se refere a seu pai em entrevistas, ou em escritos - indagando sobre a relação de sua família com a dos Wanderley do engenho Olindeta. ${ }^{17}$ Ainda, no mesmo parágrafo, ao indicar que o nome Gaspar é dado a muitos Wanderley, lembra que sua própria irmã chama-se Gasparina. Mais, quando o irmão de Dona Sinhá o chama de doutorzinho vindo de estudos no estrangeiro: “[...] eu já andei lendo escritos de vosmecê que Pedrinho de Japaranduba me mostrou. Pedrinho casado com nossa parenta Laura" (Freyre, 1967a: 128). Ainda, diretamente, logo na primeira página, Dona Sinhá falando: “O senhor não tinha que inventar uma história da minha vida, procurando, já fora de tempo - pensa que eu não sei? - ser romancista à minha custa" (Freyre, 1967a: 3). Ou quando o narrador fala de si mesmo: "[...] sou um indivíduo deformado quase profissionalmente pela preocupação sociológica com as coisas históricas: mesmo quando às voltas com outros tempos, além do histórico" (Freyre, 1967a: 19).

Não creio ser necessário apontar os muitos exemplos similares ao longo do livro. O que quero salientar é o fato de se tratar de uma narrativa especular, na qual os vários narradores se cruzam e vários tempos estão presentes; momentos do presente refletem épocas diversas da estória/história. A ideia de tempo tríbio, ${ }^{18}$ elemento importante nas teses anteriores de Freyre, é posta e reposta de muitas maneiras nesse romance. Os personagens vivenciam esses vários tempos. Além da duplicidade presente no narrador, a figura de Paulo apresenta vários traços autobiográficos do autor. Ou seja, alguns episódios da vida de Gilberto Freyre estão presentes na construção do perfil desse personagem e muitas das ideias do escritor lhe são atribuídas.

Volto à afirmação da cidade como personagem. A casa de Dona Sinhá fica no Largo de São José de Ribamar; o narrador confessa ser seu recanto predileto daquele bairro que sempre o seduziu, pois é símbolo histórico não só do Recife como da região. "Do bairro inteiro de São José se deve dizer que não é no Recife só um espaço à parte dos outros: é também um tempo diferente. Mas retardado, dizem os progressistas com algum desdém" (Freyre, 1967a: 4). ${ }^{19}$ Bairro "onde aos domingos, pela manhã, se preparavam os melhores munguzás do Recife, com um cheiro bom de milho e canela que vinha de dentro das casas até à rua" (Freyre, 1967a: 4). Trata-se de passagem quase idêntica a parágrafo do Manifesto regionalista, em parte lido no Congresso Regionalista de 1926 e publicado com acréscimos em 1952: 
Quando aos domingos saio de manhã pelo Recife - pelo velho Recife mais fiel ao seu passado - e em São José, na Torre, em Casa Amarela, no Poço sinto vir ainda de dentro de muita casa o cheiro de munguzá e das igrejas o cheiro de incenso, vou almoçar tranquilo o meu cozido ou o meu peixe de côco com pirão. Mais cheio de confiança no futuro do Brasil do que depois de ter ouvido o Hino Nacional (Freyre, 1967b: 60-61).

Não por acaso, quando o narrador deixa pela primeira vez a casa de Dona Sinhá, detém-se no Largo da Penha e entra na igreja, tentando estabelecer uma relação desta com aquela, entre a mãe, o filho padre, os frades capuchinhos e Dom Vital. Ou seja, colocando na mesma linha a domesticidade de Dona Sinhá, sua religiosidade, sua elegância discreta - mais antiga que moderna -, seu ar aristocrático, as tradições do bairro de São José, da cidade do Recife ou dos engenhos familiares de Pernambuco. ${ }^{20}$ É esse perfil que faz com que Dona Sinhá se torne para o narrador "uma sedução irresistível". Trata-se de personagem do romance, mas, na linha seguinte chega Gilberto:

Lembrei-me de Oswald de Andrade a confessar-me que estava apaixonado por uma senhora com idade de ser quase sua avó e a justificar-se: "Freud me compreenderia". E acreditei-me, embora muito menos que Oswald, um caso um tanto freudiano em minhas relações simplesmente empáticas com Dona Sinhá: mais com a imaginada por mim do que com a outra, a concreta (Freyre, 1967a: 20).

Vendo, na igreja da Penha, a gravura do bispo Dom Vital, nota sua virilidade e altivez que lhe servirão, comentará mais adiante, em suas lutas pela Igreja. Contrapõe, nesse momento, a figura viril com a do "amarelinho" - sofredor, doente, franzino. O lugar permite o retorno a velhos temas. Em Ordem e progresso Gilberto Freyre, no capítulo que discute "o progresso da miscigenação" no Brasil republicano, o perfil do "amarelinho" ocupa grande parte da reflexão, representado por figuras eminentes da política. Chamo a atenção para a distinção que faz entre indivíduos eugênicos e cacogênicos, mostrando como estes últimos ganharam espaço político e cultural com a ascensão promovida pelo novo regime - Ruy Barbosa, Barbosa Lima, Santos Dumont, Olavo Bilac, Euclydes da Cunha. Os eugênicos, em maior número, são representados por Joaquim Nabuco, Antonio Prado, Assis Brasil, Barão do Rio Branco, para citar alguns.

No romance, tanto como personagem da estória como da história, Joaquim Nabuco se destaca como indivíduo superiormente eugênico, de beleza reconhecida. Em várias passagens do livro é lembrado por seu porte aristocrático, homem de bela estampa. Paulo, ao lembrar que conhecera Nabuco jovem, na casa de Chico Canário, colecionador de passarinhos casado com Luzia, negra quitandeira, reflete: "sentir naquelas duas imagens - a de Nabuco e a de Luzia - um encanto que mais tarde lhe pareceria ter vindo do fato de haverem sido as duas primeiras grandes revelações de beleza da figura humana a seus olhos de menino. O homem superiormente belo e a mulher superiormente bela" (Freyre, 1967a: 95). A descrição dos tipos, tanto em Ordem e progresso quanto em Dona 
Sinhá, é ambígua. No livro de 1959 há uma mal disfarçada estratégia de identificação de cacogênico e mestiço, com referência ao fato de serem híbridos, negróides, com "gaforinhas um tanto rebeldes aos pentes de fabrico europeu e para cabelos de tipo europeu" (Freyre, 1959: 348). ${ }^{21}$ No romance de 1964 há a sugestão de que a beleza só está presente nos tipos raciais puros: negro e branco, Luzia e Nabuco.

\section{A MARCA DO TEMPO}

Nas andanças pela cidade, o narrador reconstitui o tempo. No romance os vários tempos estão entrelaçados e aparecem sem linhas definidas. Dona Sinhá jovem, José Maria bebê, adolescente, sua entrada no seminário, localizam-se no período do Segundo Reinado. A morte de José Maria, o retorno de Paulo Tavares da Europa, seu pedido de casamento a Dona Sinhá se encontram nos primeiros anos da República. A intimação recebida pelo narrador para que compareça à casa de Dona Sinhá, o encontro com Gaspar, e a pesquisa para reconstituição da vida dos vários personagens, ocorrem entre o final de 1920 e os primeiros anos de 1930. A escritura do livro é, evidentemente, posterior. Ilustro. Quando o narrador conhece Gaspar, irmão de Dona Sinhá, e passa a se encontrar com ele para ouvir sua versão sobre os acontecimentos, certa vez almoça no Dudu, no pátio do Mercado de São José. Quando escreve a história, recordando as narrativas dos diversos personagens, o restaurante não mais existe. "Dudu: o dono de um restaurante popular como nunca mais, depois dele morto, haveria outro igual no Recife" (Freyre, 1959: 13). A cidade marca o tempo.

A vida de José Maria e os acontecimentos imediatamente posteriores à sua morte ocorrem numa época de transição do trabalho escravo para o trabalho livre e proclamação da República. Portanto, a estória/história corresponde ao período focalizado por Gilberto Freyre em Ordem e progresso. Neste livro, o elemento que preside a reconstituição da sociedade brasileira no meio século estudado é a afirmação de não existirem rupturas na ordem social em relação ao período anterior. No romance, as alterações entre os tempos são só aparentes. Por exemplo: a "negra Inácia, que a acompanhara do engenho, como presente do Pai", de mais confiança do que as outras negras (Freyre, 1967a: 22), nos diferentes momentos é tratada por Dona Sinhá como escrava. Quando a repreendia por ensinar a José Maria palavras "plebeias" ou de origem africana, ameaçava-a de mandar coser sua boca como a dos sapos: "É mesmo o que eu devia fazer. Tu tens mesmo boca de sapo. Mais de sapo do que de gente, negra atrevida que só nasceste pra senzala de engenho" (Freyre, 1967a: 29). Ou avisava ao filho que Inácia era pessoa muito boa "mas não deixava de ser negra. [...] que não acreditasse em coisas de negro. Isso de Iemanjá era invenção de negro" (Freyre, 1967a: 23). Assim, a condição escrava apar- 
ce, mas não é tematizada, fica numa espécie de limbo e como se as relações fossem sempre cordiais.

Mas é Inácia quem acompanha o menino à rua, às águas, ao largo da Igreja de São José do Ribamar, que lhe apresenta a cidade. "Ele dificilmente se imaginava sem Inácia e guiado pelo português errado da negra [...] é que ele descobrira o ribamar, o rio, os peixes, a tal de Iemanjá que sua mãe negava" (Freyre, 1967a: 29). Ao andar pelas ruas e pela praia com ela passa a conhecer as várias facetas e cores do mundo, que a austeridade da vida em casa não permitia. Assim, o menino foi descobrindo

[...] novas formas, novas cores, novos sons, que se juntavam às palavras e aos modos aprendidos com Dona Sinhá para o separarem de Inácia, das outras negras, dos muleques, dos pescadores de Ribamar, de suas várias deformações do português em língua, ora muito cheia de palavras vindas da África, ora muito adoçada em língua para menino e para escravo, sem rr nem ss, nem 11 (Freyre, 1967a: 31-32, grifos meus).

A tese da existência de dois mundos antagônicos, mas em equilíbrio, desenvolvida em Casa-grande \& senzala, no qual "as palavras sem ossos" exercem um papel de aproximação entre opostos, está aqui presente.

Apenas numa passagem do romance percebemos a clara marca do tempo: o retorno de Paulo da Europa, onde fora estudar medicina. Chegando ao cais, "viu no primeiro escaler a aproximar-se do vapor inglês, a bandeira com seu 'Ordem e Progresso'. Deixara o Brasil sob a bandeira do Império” (Freyre, 1967a: 87). No livro Ordem e progresso este é o mote para a reflexão sobre a recepção da mudança de regime pela população brasileira. E. F. Knight, um inglês, aportara em Salvador em meados de 1889. Voltando em 1890 depara-se, no porto e nas embarcações, com uma nova bandeira. Intrigado, pergunta ao remador o significado daquela mudança. "O negro lhe explicou, com 'um ar indiferente': 'Ah, a República'. Friamente; sem se exaltar com o fato” (Freyre, 1959: 5). Ao inglês, a reação induziu a que rotulasse o povo brasileiro como apático, indolente, quase oriental. Mas para Gilberto Freyre, o episódio coloca o tema central do livro: não existiram rupturas importantes com a mudança de regime. Ao contrário, aristocratas anteriormente defensores da monarquia aderem prontamente à República, ocupando cargos, esquecendo antigos favores e velhas polêmicas. Para o povo, a situação continua a mesma.

A cidade havia mudado, embora pouco. "Paulo veio encontrar no seu Recife, ao lado de muita coisa do seu tempo de menino e adolescente, algumas modernices, umas que lhe agradaram, outras que lhe pareceram abomináveis" (Freyre, 1967a: 118). Nota com desagrado a troca dos nomes das ruas. Ainda, a invasão "do móvel chamado austríaco que começava a substituir jacarandás e vinháticos dos melhores. [...] outra invasão: a da cama de ferro" (Freyre, 1967a: 120). ${ }^{22}$ São José do Ribamar pouco mudara. "O tempo quase não passara sobre a maioria dessas casas. As mesmas casas. Os mesmos sobrados. As mesmíssimas igrejas. As próprias pessoas, quando não eram as mesmas [...] pareciam 
as mesmas" (Freyre, 1967a: 135). Claro que não se parecia com os bairros mais ricos, cujo furor da modernização tudo alterava. Continuava sendo o lugar em que rio e mar se encontravam - ribamar - paraíso dos pescadores.

Impressionou-o, ainda, a rapidez com que as pessoas alteraram suas posições políticas. Conservadores ferrenhos no passado declaravam ter sido sempre abolicionistas e republicanos. Por exemplo, ouvindo o ex-sócio do pai, grande comerciante de açúcar que "abaixando a voz [diz] 'Olha, Paulo, bem sabes que sempre fui simpático à República. Que sempre pertenci ao número dos imbaronáveis'[...]" (Freyre, 1967a: 107). Tavares sorriu ante o neologismo e entendeu que o velho amigo almejava cargo político. Outra vez a mesma ironia gilbertiana de Ordem e progresso, lembrando que barões, viscondes e conselheiros do Império, logo após o pronunciamento de 15 de Novembro mostraram sua adesão e obediência, desejando que se consolidasse a ordem, a integridade e a prosperidade (Freyre, 1959: 6). Ou como o Conselheiro José Antonio Saraiva aconselhando, por ser a República fato consumado, que "devemos adotá-la e servi-la lealmente” (Freyre, 1959: 7). Vários amigos de Paulo afirmavam - antes a ordem do que a anarquia - como algumas pessoas entrevistadas por Gilberto Freyre para o livro de 1959.

Vale assinalar, ainda, que o narrador conta um pouco, através das experiências europeias de Paulo, a vivência de Gilberto em sua primeira viagem à Europa, embora estas estejam localizadas em outro tempo. Tavares abandona suas posições positivistas e spenceristas ao ler a obra de Newman e tal foi seu entusiasmo "que largou-se um dia, de Paris, para a Inglaterra, só para conhecer Oxford. A Oxford de Newman. E na Oxford de Newman lembrou-se muito de José Maria, ao ver dois inglesinhos de beca em plena efusão de amizade amorosa que lhe pareceu, no melhor sentido da palavra, platônica" (Freyre, 1967a: 117-118). ${ }^{23}$ O conhecimento da obra de Newman lhe permitiu chegar a um "outro modo de considerar a vida, o homem, o lugar da ciência no saber humano" (Freyre, 1967a: 117). É conhecida a frase do diário de Freyre, supostamente escrita em 1922 "venho encontrando em Oxford meu ambiente como em nenhum lugar já meu conhecido" (Freyre, 1975: 104). Comenta, ainda, em várias ocasiões, a influência que Pater e Newman exerceram sobre ele. Pallares-Burke assinala que Freyre refere-se a autores ingleses como sendo seus pais espirituais: Newman, Walter Pater, Zimmerman, Robert Louis Stevenson. Lembro que a tese de Zimmerman sobre os escravos da Grécia antiga serviu de apoio à reflexão sobre o papel do escravo africano como cocivilizador da sociedade colonial brasileira. Ou como aponta a autora, "uma de suas ideias-chave, 'equilíbrio de antagonismos', também era considerada por Freyre como parte essencial do ethos inglês e como 'a lição dos ingleses' para o mundo" (Pallares-Burke, 2005: 41).

Destaco que a discussão dos antagonismos em equilíbrio, expressão central na interpretação freyriana da sociedade brasileira, é tributária da teoria spenceriana, embora Freyre a encontre por meio da leitura de Carlyle. Geralmente 
as interpretações dos analistas sobre esse tema em Freyre assinalam o aspecto comportamental do equilíbrio de opostos, configurando zonas de confraternização social no Brasil. Chamo a atenção para outro aspecto da interpretação freyriana, aliás presente naqueles autores ingleses. Tanto nestes como em Gilberto, o equilíbrio de antagonismos tem um efeito político, a conciliação. É este um dos temas principais de Ordem e progresso. O autor não só descreve as diferentes formas de conciliação política, como, em várias passagens, aponta-as como virtudes. Mostra como as diversas crises nos primeiros anos republicanos resolveram-se a partir desses arranjos. A presença da monarquia se dá mediante os conselheiros, viscondes e barões com responsabilidades no governo republicano. Mais ainda, retomando a revalorização do Exército, esquecido por D. Pedro II, lembra seu papel diferenciado em relação a outros países sul-americanos, "principalmente na constância pacifista que tem animado no Brasil as Forças Armadas: quase sempre, forças de pacificação ou de conciliação nas crises políticas nacionais de nosso país" (Freyre, 1959: 81). Também, no romance, várias vezes Paulo Tavares reflete sobre as vantagens da conciliação política.

Poderia ir mais longe nas aproximações entre Gilberto Freyre e seus personagens. Porém, creio que os exemplos dados permitem traçar o perfil do romancista: um escritor longe dos modelos cartesiano ou positivista, interpretando a realidade a partir de uma perspectiva personalista. Como gostava de definir-se, um escritor ibérico que ajusta a palavra à sua personalidade em vez de ajustar a personalidade a qualquer conjunto de convenções de arte literária escrevendo à revelia de quase todas as convenções literárias. Que intensifica a realidade para, assim, compreendê-la, dramatizá-la e interpretá-la, inventar o real, substituindo uma perspectiva única por perspectivas empáticas e simultâneas da mesma realidade. Capaz de redimensionar o mundo baseando-se na intensificação de fatos, misturando pessoas e tempos diversos, buscando novas combinações de relações reais de pessoas com paisagens. Operar com a autobiografia, não sendo inventor de personagens ou de mitos, tendo por base a própria experiência. Arriscar-se a buscar um modo de escrever no passado, nas tradições do povo, sem tornar-se arcaico (Freyre, 1968: 172-176). Trata-se de um escritor simultaneamente expositor e narrador. De certo modo, o autor é personagem de si mesmo; ou melhor, os personagens fictícios servem para que reitere suas ideias, funcionando como seu alter ego.

São esses traços que permitem a Gilberto transformar a cidade em personagem, tornando-a mediadora entre a estória e a história. 
Elide Rugai Bastos é professora titular do Departamento de Sociologia do Instituto de Filosofia e Ciências Humanas (IFCH) da Universidade Estadual de Campinas (Unicamp) e pesquisadora do Conselho Nacional de Desenvolvimento Científico e Tecnológico (CNPq). O presente artigo faz parte de um Projeto Temático, do qual é coordenadora, financiado pela Fundação de Amparo à Pesquisa do Estado de São Paulo (Fapesp). É autora dos livros Gilberto Freyre e o pensamento hispânico (2003) e As criaturas de Prometeu: Gilberto Freyre e a formação da sociedade brasileira (2006). 


\section{NOTAS}

1 Dedico este trabalho à memória de Roberto Ventura. $\mathrm{O}$ artigo em sua primeira versão estava escrito há dez anos. Roberto Ventura, no início de 2002, ministrava um curso sobre pensadores brasileiros na Unicamp, no qual me incluíra como expositora de um seminário e para o qual redigi uma primeira versão deste texto. Depois de sua trágica morte nesse mesmo ano não quis voltar ao tema. Incluindo inúmeras sugestões feitas por ele, retomo-o agora, acrescentando leituras feitas posteriormente.

2 Sabemos que o diário, publicado em 1975, baseado, segundo Freyre, em anotações dos anos 1915 a 1930, contém inserções que comportam explicações de elementos de sua obra posterior. No entanto, o utilizo, pois quero indicar a importância de Federico De Onis em sua formação acadêmica.

3 A tradução é minha.

4 Sobre a influência dos escritores espanhóis remeto a meu livro Gilberto Freyre e o pensamento hispânico: entre Dom Quixote e Alonso El Bueno (2003), no qual procuro apontar a presença de alguns desses autores na construção da temática e do estilo de Freyre.

5 Trata-se do texto Social life in Brazil in the middle of the nineteenth century. Original datilografado, Butler Library, Columbia University, 1922. Publicado em português em 1964.

6 No ensaio "O tempo da casa-grande", Glaucia Villas Bôas (1988) denuncia esse equívoco, aprofundando a argumentação, o que me libera do desenvolvimento da crítica.

7 Referindo-se à atuação de Gilberto Freyre no A Província, Edson Nery da Fonseca diz: "Publica no mesmo jornal artigos e caricaturas com diferentes pseudônimos: Esmeraldino Olímpio, Antônio Ricardo, Le Moine, J. Rialto e outros" (Fonseca, 1977: 45). As pesquisadoras da Fundação Joaquim Nabuco (Fundaj), Lúcia Gaspar e Virgínia Barbosa, em "Gilberto Freyre, jornalista: uma bibliografia” (2010), listam os artigos publicados no A Província, com os pseudônimos Antônio Ricardo, Jorge Rialto e Raul dos Passos.

8 Os dados que apresento sobre o jornal A Província obtive-os a partir do texto de Mariana Miggiolari Chaguri, Região 
e Nação: produção e circulação de ideias (2011). Agradeço a possibilidade de acesso ao texto antes de sua publicação.

9 Na obra posterior de Gilberto Freyre o termo mocambo será substituído por mucambo, mais próximo à fala regionalista.

10 "Em outubro de 1930 ocorreu-me a aventura do exílio. Levou-me primeiro à Bahia; depois a Portugal, com escala pela África. O tipo de viagem ideal para os estudos e as preocupações que este ensaio reflete". São palavras de Gilberto Freyre no primeiro parágrafo do prefácio à primeira edição de Casa-grande \& senzala (1933: IX).

11 Utilizo a primeira edição de Sobrados e mucambos, publicada em 1936. A segunda edição, de 1951, foi refundida pelo autor, acrescida de importante introdução, de cinco capítulos e numerosas notas. Como minha intenção neste artigo é mostrar o desenrolar das mudanças e permanências em relação ao tema cidade no itinerário intelectual de Gilberto Freyre, essa precaução é necessária. Utilizo também a primeira edição de Casa-grande \& senzala, de 1933.

12 O título de 1936 é Sobrados e mucambos: decadência do patriarcado rural no Brasil. O de 1951, além das alterações já indicadas, apresenta modificações: Sobrados e mucambos: decadência do patriarcado rural e desenvolvimento do urbano.

13 Tive oportunidade de discutir algumas dessas críticas no texto "Raízes do Brasil - Sobrados e mucambos: um diálogo". Ver Monteiro \& Eugênio (2008).

14 Caio Prado Jr. já havia publicado Evolução política do Brasil (1933), Formação do Brasil contemporâneo (1942) e História econômica do Brasil (1945).

15 A essa série, oficialmente composta por Casa-grande \& senzala, Sobrados e mucambos e Ordem e progresso, é importante acrescentar o livro Nordeste (1937). Deve-se assinalar que vários outros livros e artigos completam tematicamente esse projeto.

16 Compreende os livros Dona Sinhá e o filho padre e sua sequência, O outro amor do doutor Paulo (1977).

17 "Não pensou um jornalista carioca a primeira vez que chegou à nossa casa e apareceu o velho Freyre, meu Pai, trata-se de um inglês?" (Freyre, 1964: 42). Isto porque os Wanderley, 
Van der Ley, teriam aportado em Pernambuco com Maurício de Nassau, e apresentam em muitos casos traços holandeses - louros de olhos azuis.

18 Tive ocasião de explicitar essa tese, sua origem e seus efeitos em Bastos (2003), em especial no capítulo 3.

19 Como nas interpretações presentes em Introdução à história da sociedade patriarcal no Brasil, tempo e espaço aparecem superpostos.

20 Os filhos de Dona Sinhá são celebrados por seus conhecidos como os melhores da cidade. Por isso não resisto e transcrevo um trecho do Manifesto regionalista, em sua edição de 1967. "As novas gerações de moças já não sabem, entre nós, a não ser entre a gente mais modesta, fazer um doce ou guisado tradicional ou regional. Já não têm gosto nem tempo para ler os velhos livros de receitas de família. Quando a verdade é que, depois dos livros de missa, são os livros de receitas de doces e guisados os que devem receber das mulheres leitura mais atenta. O senso de devoção e o de obrigação devem completar-se nas mulheres do Brasil, tornando-as boas cristãs e, ao mesmo tempo, boas quituteiras, para assim criarem melhor os filhos e concorrerem para a felicidade nacional" (Freyre, 1967b: 60).

21 Já me referi anteriormente neste artigo, à forma pouco simpática que, em artigo de 1925, Freyre se refere aos mulatos.

22 Já assinalei anteriormente o fato de Paulo Tavares refletir em seu perfil traços autobiográficos de Gilberto Freyre. Várias das observações feitas pelo personagem estão presentes nos artigos do autor publicados após 1923, isto é, depois de seu retorno ao Recife, decorridos cinco anos de ausência. Deixo de indicar os artigos, pois se encontram citados no início deste texto.

23 Numa passagem em itálico, portanto fazendo parte da história, o narrador do romance diz, referindo-se a José Maria, cujo retrato lembrava a figura de um anjo: "Um tanto desse todo esquisitamente angélico, que eu ainda conheci em certos adolescentes ingleses, estudantes numa Oxford que quase já não existe, desfigurada que vem sendo pelo tempo social" (Freyre, 1964a: 82). 


\section{REFERÊNCIAS BIBLIOGRÁFICAS}

Bastos, Elide Rugai. As criaturas de Prometeu: Gilberto Freyre e a formação da sociedade brasileira. São Paulo/Recife: Global/ Fundação Gilberto Freyre, 2006.

Gilberto Freyre e o pensamento hispânico. São Paulo/Bauru: Sumaré/Anpocs/Edusc, 2003.

Burke, Peter \& Pallares-Burke, Maria Lúcia. Repensando os trópicos: um retrato intelectual de Gilberto Freyre. São Paulo: Ed. Unesp, 2009.

Calvino, Italo. As cidades invisíveis. São Paulo: Companhia das Letras, 1990.

Chaguri, Mariana Miggiolari. Região e Nação: produção e circulação de ideias. Campinas, 2011, mimeo.

Díaz Quiñones, Arcadio. Sobre los princípios: los intelectuales caribeños y la tradición. Bernal: Universidad Nacional de Quilmes, 2006.

Fernando Ortiz e Allan Kardec: espiritismo e aculturação. Lua Nova: Revista de Cultura e Política, 2011, 82, p. 109-138. Dimas, Antônio. Um manifesto guloso. In: Quintas, Fátima (org.). Freyre, Gilberto. Manifesto regionalista. 7.ed. revista e aumentada. Recife: Fundaj/Massangana, 1996, p. 23-45.

Coutinho, Edilberto. A imaginação do real: uma leitura da ficção de Gilberto Freyre. Rio de Janeiro/Brasília: José Olympio/INL, 1983.

Fonseca, Edson Nery da. Cronologia da vida e da obra. In: Freyre, Gilberto. Obra escolhida. Rio de Janeiro: Nova Aguilar, 1977, p. 41-66.

Freyre, Gilberto. Casa-grande \& senzala. Rio de Janeiro: Schmidt, 1933.

- Sobrados e mucambos. 1.ed. São Paulo: Companhia Editora Nacional, 1936.

. Sobrados e mucambos. 2.ed. Rio de Janeiro: José Olympio, 1951.

. Interpretação do Brasil. Rio de Janeiro: José Olympio, 1947.

(vol. 1)

Ordem e progresso. Rio de Janeiro: José Olympio, 1959. 
. Dona Sinhá e o filho padre. Rio de Janeiro: José Olympio, 1964a.

Retratos de jornais velhos. Rio de Janeiro: José Olympio, 1964b.

Manifesto regionalista. 4.ed. Recife: Instituto Joaquim Nabuco de Pesquisas Sociais, 1967.

. Como e porque sou e não sou sociólogo. Brasília: Ed. UnB, 1968.

Tempo morto e outros tempos: trechos de um diário de adolescência e primeira mocidade. Rio de Janeiro: José Olympio, 1975.

. Vida social no Brasil nos meados do século XIX. 2.ed. Rio de Janeiro/Recife: Artenova/Instituto Joaquim Nabuco de Pesquisas Sociais, [1964] 1977.

. Tempo de aprendiz: artigos publicados em jornais na adolescência e na primeira mocidade do autor: 1918-1926. São Paulo/Brasília: Ibrasa/INL, 1979a e 1979b. (vol. I e II)

Ganivet, Ángel. Idearium español. Madri: Biblioteca Nueva, [1897] 1996.

Gaspar, Lúcia \& Barbosa, Virgínia. Gilberto Freyre, jornalista: uma bibliografia. Recife: Fundação Joaquim Nabuco, 2010. Disponível em <http://www.fundaj.gov.br/geral/2010anojn/ gilbertofreyrejornalistabibliografia.pdf $>$. Acesso em 10 maio 2012 .

Gomes, Ângela de Castro (org.). Em família: a correspondência de Oliveira Lima e Gilberto Freyre. Campinas: Cecult/Mercado de Letras, 2005.

Monteiro, Pedro Meira \& Eugênio, João Kennedy. Sérgio Buarque de Holanda: perspectivas. Campinas/Rio de Janeiro: Ed. Unicamp/Ed.Uerj, 2008.

Motta, Mauro (org.). Liuro do Nordeste. 2.ed. fac-similar. Recife: Arquivo Público Estadual de Pernambuco, [1925] 1979.

Pallares-Burke, Maria Lúcia. Gilberto Freyre: um vitoriano dos trópicos. São Paulo: Ed. Unesp, 2005.

Ramos, Julio. Desencuentros de la modernidad en América Latina: literatura y política en el siglo XIX. México: Fondo de Cultura Económica, 1989. 
GILBERTO FREYRE: A CIDADE COMO PERSONAGEM

I58

Said, Edward W. Beginnings: intention and method. NovaYork:

Columbia University Press, 1975.

Cultura e imperialismo. São Paulo: Companhia das

Letras, 1995.

Villas Bôas, Glaucia. O tempo da Casa Grande. Dados, 1988, 31/3, p. 343-55. 


\section{Palavras-chave: Resumo:}

Gilberto Freyre; A partir da leitura do romance Dona Sinhá e o filho padre, esDona Sinhá e o filho padre; crito em 1964, o artigo pretende mostrar a centralidade do

Pensamento brasileiro; tema "cidade" na obra de Gilberto Freyre. Partindo de sua Tradição; Modernização. correspondência dos primeiros anos nos Estados Unidos e seus artigos no jornal Diário de Pernambuco, examina o modo pelo qual o sentido atribuído à cidade na formação nacional se transforma no decorrer de sua obra. A relação entre o tradicional e o moderno é a chave que conduz sua interpretação da sociedade brasileira.

\section{Keywords: Abstract:}

Gilberto Freyre; Based upon a reading of the novel Mother and son, a BrazilMother and son, a Brasilian tale; ian tale, written in 1964, this article shows the centrality of Brazilian thought; the "city" in the work of Gilberto Freyre. Grounded in his Tradition; Modernity. correspondence from the first years in the United States, as well as articles published in the Diário de Pernambuco, it examines how the meaning attributed to the city changes throughout his work. The relationship between the modern and the traditional is key to Freyre's interpretation of Brazilian society. 